\title{
FACTORS INFLUENCING PRICES AND FREQUENCIES IN THE INTERURBAN BUS MARKET: EVIDENCE FROM EUROPE
}

\author{
Xavier Fageda and Sergi Sansano \\ (University of Barcelona)
}

\begin{abstract}
We analyze the determinants of prices and frequencies in the interurban bus services (IBS) market. Drawing on data collected from a sample of routes in six large European countries, we find that intramodal competition is based on frequencies while intermodal competition is based on prices. Furthermore, we provide evidence of the regressive nature of the IBS in Europe by showing that routes with low-income endpoints face higher prices. We also find significant price differences between countries, which can be attributed to differences in their respective regulatory systems.
\end{abstract}

Keywords: Interurban bus, prices, frequencies, intramodal competition, intermodal competition, low-income users. 


\section{Introduction}

Interurban bus services (IBS), unlike other modes of transport, such as air and high-speed rail (HSR) travel, do not typically attract the attention of the media or academia. Yet, interurban buses offer a number of advantages. For example, they cover similar routes, usually at lower prices, to those provided by these alternatives modes and, moreover, there is no need to invest in new, costly infrastructure to operate a route, as is obviously the case with HSR (DfT, 2004a). According to Eurostat data, in 2013, passenger buses and coaches accounted for $9.2 \%$ of inland passenger transport in the EU-28, while trains accounted for $7.4 \%{ }^{1}$

The prices charged by this mode are especially attractive to lower income groups, including the young, the elderly and those without access to a car. ${ }^{2}$ In this regard, Balcombe et al. (2004) calculate that interurban bus users have a lower value of time than that of train users.

Promoting the use of IBS also helps reduce the congestion caused by cars (DfT, 2004a) and air pollution levels (Heil and Pargal, 1991; Stanley and Watkiss, 2003; Chapman, 2007). All in all, IBS ensure that there are fewer vehicles on the roads. Indeed, Abuhamoud et al. (2002) claim that a double-decker bus is a sustainable mode of transport and can replace up to 50 other motorized vehicles. Note also that the relationship between buses and road safety outcomes is complex but recent studies suggest that the marginal external accidents cost per passenger kilometer of buses is lower than that of cars (Sen, 2010; Rizzi and De La Maza, 2017). ${ }^{3}$

\footnotetext{
${ }^{1}$ Note here that Eurostat data do not differentiate between local and longer distance bus.

${ }^{2}$ Surveys report that $40 \%$ of regular bus users in the UK and $50 \%$ in Greece live in households without access to a car (European Commission 2009).

${ }^{3}$ Accident cost is a function of accident rate and accident severity (Jansson, 1994). Severity is influenced by speed and rate by the number of vehicles. A greater presence of buses on the roads may decrease the number of accidents as they can each substitute many cars. However, more buses could increase the severity of accidents if they help to increase the speed of cars on the road.
} 
Studies about the performance of bus services have usually focused on urban transportation. A typical concern here has been to determine the effect of ownership on efficiency. For example, Albalate et al. (2012) analyzed urban bus transportation in the city of Barcelona (Spain), concluding that the most efficient way to deliver urban bus services was via partial privatization. Vining and Boardman (1992) found privately owned bus companies to be more efficient than their public counterparts, while Jørgensen et al. (1997) found no differences between public and private companies in Norway. Other studies, including Borcherding et al. (1982) and Scheffler et al. (2013), report that a more important determinant of efficiency is the presence or otherwise of competition on a route rather than the ownership structure of the bus companies. ${ }^{4}$ Further to this, some recent studies do not find significant differences in the costs of urban bus lines between those operated under competitively tendered contracts and those operated under performance-based negotiated contracts (Fillipini et al., 2015; Mouwen and van Ommeren, 2016). A common explanation for that result is that the threat of competitive tendering is sufficient to put pressure on the behavior of operators. An extensive literature review can be found in Ibarra-Rojas et al. (2015).

Interurban bus services, particularly regarding competition and the effects of liberalization, has not been widely studied. Van de Velde $(2009,2014)$ reviewed the interurban bus regulatory systems being operated in Europe, and found that competition in the market, rather than tendering concessions (competing for the market), was the most frequent form of competition in Europe. Knorr and LuegArndt (2016) and Dürr and Hüschelrath (2017) provide data that show an important increase in the number of routes served by the German interurban bus market just after its deregulation. For the same market, Dürr et al. (2016) show price increases on duopoly routes as a consequence of the merger between two big players. Augustin et al. (2014) compare the German and US markets suggesting the

\footnotetext{
${ }^{4}$ Taylor and Ciechanski (2008) analyze changes in ownership involving Poland's road transport firms after 1990 and they conclude that state ownership remains dominant.
} 
higher potential of the former due to its lower average distances. ${ }^{5}$ Blayac and Bougette (2017) find that the liberalization of French long-distance bus services has had positive effects in terms of fares, number of operators and frequencies. Aarhaug and Fearnley (2016) document a steady traffic growth in the inter-urban market in Norway after its liberalization. Finally, Alexandersson et al (2010) argue that the Norwegian market is more developed and efficient compared to its Swedish counterpart.

Other studies compare IBS with the services provided by other transport modes, especially rail. For example, Bataille and Steinmetz (2013) examined the effect of introducing interurban buses to compete with trains, while Ahern and Tapley (2008) compared interurban rail and bus passenger preferences in Ireland by combining revealed and stated preference models. Finally, Rojo et al. (2012) analyze which variables affect the probability that a traveler will use a bus or a car for an inter-city journey, by applying different discrete choice models in a dataset based on survey results from a region in Spain. They show that prices, frequencies and the duration of the journey have a relevant influence on modal choice.

We seek to add to this literature by undertaking an empirical analysis of the determinants of prices and frequencies in the interurban bus market through a comparison across countries. To do this, we collected data on routes from a number of large European countries, including France, Germany, Italy, Spain, Sweden and the United Kingdom. Data for the main variables are from May 2015. We focus our attention specifically on the presence of different transportation modes on the routes and the factors characterizing the firms' intramodal competition as well as the regulatory system in operation in each country. Additionally, we analyze whether prices relate to income levels at the route endpoints.

\footnotetext{
${ }^{5}$ Walter et al. (2011) analyze the inter-urban bus market in Germany before the liberalization took place. By analyzing demand and supply in the long-distance transportation market, they predicted that the share of bus services after the liberalization could be about $5 \%$.
} 
The main results from this analysis indicate that bus prices are lower on routes with richer endpoints; thus, we provide some evidence of a regressive fare-setting scheme in the countries examined. We also find that in the interurban bus market intramodal competition is based on frequencies while intermodal competition is based on prices. Finally, we find substantial differences across the countries examined, which could be attributed to differences in the regulatory model in operation in each country.

The rest of the paper is organized as follows. Section 2 describes the data used and outlines the methodology employed in analyzing the determinants of prices and frequencies in the interurban bus market. A priori expectations of the explanatory variables are considered in section 3 , while the estimate results are presented in section 4. Finally, section 5 concludes.

\section{Data and methodology}

\subsection{Sample}

The sample used in the empirical analysis includes observations for the United Kingdom, Germany, Italy, France, Spain and Sweden. Since both the availability and quality of data differ across countries, we opted to include the five largest EU Member States plus Sweden; the countries with the best data available.

Our unit of observation for the empirical analysis is the routes linking two endpoints. For each country, we include 45 potential links; the result of interconnecting each country's ten largest cities. In each case, the origin is the city with the larger population. Thus, Germany is the country offering most bus routes (with a total of $41^{6}$ ), followed by Spain (38), the United Kingdom (37), Italy (25),

\footnotetext{
${ }^{6}$ In the case of the four remaining routes, two - Düsseldorf-Essen and Dortmund-Essen - link cities that are less than $50 \mathrm{~km}$ apart. According to the German model, interurban buses cannot operate on a route that is under $50 \mathrm{~km}$.
} 
Sweden (23) and France (13). This gives us 177 interurban bus services for a total of 270 potential links.

In our analysis, we only consider direct routes (but include those that make stops en route); after all, identifying all the indirect routes is hardly feasible. By using this strategy, we ensure that our eventual sample is more closely comparable across countries. Having identified which bus company (or companies) provides a service on a given route, we then visit their website(s) and complete all the steps required to book a ticket. In this way we obtain the data for our dependent variables, i.e. the mean price and total frequency at the route level. The duration of each journey is also obtained directly from these websites. Only in the case of Spain did we find information regarding bus capacity, which would have been a relevant variable to include in the model had it been available across the countries.

There are often different routes available for linking up a pair of cities but the bus companies do not provide these details; therefore, we have opted to use the fastest route provided by Google Maps to measure the total distance between two cities. Once we know the length of the journey and the journey time, we can easily calculate the average speed for each route and determine one of our main dependent variables, i.e. price per kilometer. Data for the rest of the variables included in the analysis were obtained from Eurostat.

The main characteristics of the regulatory system being operated in each of the countries included in our analysis are summarized below using information provided by the European Commission (2009), Van de Velde (2009) and Barbadillo et al. (2014).

In the United Kingdom, the sector underwent a liberalization process with the introduction of the 1980 Transport Act and the privatization of the National Bus Company, now National Express (NE) ${ }^{7}$.

\footnotetext{
${ }^{7}$ White and Robbins (2012) analyze the competitive strategies followed by NE to respond to the competitive pressure imposed by Megabus.
} 
However, it was not until 2003 that NE's main competitor, Megabus, entered the market. In the United Kingdom, bus companies are free to choose the routes they operate, the frequency of services offered and the fares charged, and the degree of regulation is minimal. The Traffic Commissioners guarantee that there are no collusive and anti-competitive agreements among the UK's agents.

The Swedish market has also been liberalized, however the number of services remains low. Deregulation was initiated in 1993 and terminated in 1999, with firms being allowed to operate even if their presence was reported as being detrimental to train services. As in the UK, firms are free to fix routes, frequencies and fares. Swebus and Nettbus are the leading firms in the Swedish interurban bus market.

In Italy, the system has been liberalized since 2005. Yet, the oligopolistic power of the traditional firms; the complexity and discretion entailed in the authorization of licenses; and, the competition with what are typically subsidized train services, all represent major entry barriers for new firms. The corporate group made up of Baltour, Sena and Eurolines dominates the market, although there are many local operators.

In Spain, the IBS were under state control until 1990. Today, however, firms compete for the market through competitive tendering. The length of the concessions (between 8 and 20 years) and the fact that "concession competitions favor incumbents" (European Commission 2009, p 52) represent a significant entry barrier for new firms. The country's largest operator is ALSA.

Until 2011, bus firms in France were not allowed to operate services on routes covered by the national railway company $(\mathrm{SNCF})$, which meant the IBS were marginal. Although the market was opened up between 2012 and 2013, the level of usage of interurban bus services has been much lower than in countries such as Spain. In fact, in our sample, France has by far the fewest interurban bus connections, followed by Sweden and Italy. Note here that our data are not able to capture the 
influence of the liberalization of the long-distance bus market in France that took place in the summer 2015.

Finally, until 2012, Germany operated a very similar regulatory system to the one used in France. The policy was designed to promote and protect rail transport and, in general, prohibited IBS. However, in 2013 with the passing of the "Personenbeförderungsgesetz", the authorities liberalized the market. Today, any firm is free to operate in the market as long as the distance of the route is at least $50 \mathrm{~km}$ and the journey time is more than an hour. Postbus, Flixbus and Berlinlinenbus are the main operators in Germany. ${ }^{8}$

For illustrative purposes, Table 1 summarizes the number of IBS routes and their daily frequencies in each of the six countries. The second column lists the firms offering IBS in each country. We also show the number of routes that each company operates and the total daily frequencies, in the third and fifth columns, respectively. Note that we could have missed out smaller operators so that more services may exist.

The table allows us to determine whether differences in countries' regulatory systems are translated into different levels of IBS provision. By way of example, let us take the cases of Spain and the United Kingdom, two countries operating quite distinct regulatory systems. As explained above, Spanish firms compete for the market through competitive tendering while UK firms freely compete in the market. In the case of Spain, we find bus services operating on 38 routes (from a possible 45) and the sum of the daily frequencies on these routes is 229 . Of these 38 routes, ALSA controls 28, which means one firm provides $73.7 \%$ of the IBS in Spain. Moreover, in terms of daily

\footnotetext{
${ }^{8}$ Knorr and Lueg-Arndt (2016) provide some data on the evolution of the German market for intercity bus services in the two years after the liberalization. They show a rapid growth in terms of the number of lines operated, the passenger volume and the number of buses in operation on scheduled services. They also observe a consolidation trend in the sectors through mergers and exits.
} 
frequency, the firm controls $81.7 \%$ of the total market, offering 187 of the 229 journeys operated each day in Spain.

\section{Insert table 1 about here}

In the case of the United Kingdom, $51.4 \%$ of the routes (but only $13.3 \%$ of the total daily frequency) are offered solely by NE, while the remaining $48.6 \%$ ( $86.7 \%$ of the total daily frequency) are offered both by NE and Megabus (note, the label 2 (or 3) is used whenever 2 (or 3) firms operate services on the same route). Column seven shows that on those routes operated by both firms, NE offers a slightly higher frequency than that offered by Megabus (258 vs 191). Thus, in the UK, NE is responsible for $63.15 \%$ of daily journeys, i.e. six out of ten buses offering interurban services belong to $\mathrm{NE}^{9}$. So, while it is evident that the number of firms operating in Spain is higher than in the UK (6 vs 2), the level of competition in Spain is considerably lower, given that one firm is responsible for more than $80 \%$ of the country's daily frequency.

All in all, Table 1 allows us to identify differences between the countries with regard to the number of routes operated, the daily frequency of services, the number of firms providing any given service and, ultimately, the level of competition in each country.

\subsection{Variables}

The dependent variables in our analysis are prices per kilometer and frequencies. In comparing prices across the six countries, we introduce a purchasing power parity (PPP) factor and divide the price per kilometer by the corresponding PPP index. In so doing, we obtain a more comparable

\footnotetext{
${ }^{9}$ These results are not, of course, applicable for the whole country, but refer only to the routes interconnecting the ten largest cities in the UK (see earlier explanation).
} 
variable than current market prices ${ }^{10}$. Prices and frequencies correspond to 12 May $2015^{11}$ and they were collected one month in advance.

As in other transport sectors (including air and rail), the prices for IBS are not uniform and may vary for several reasons, including demand, day of booking, etc. For this reason, we identify three different prices per service: the price for the earliest departure, the lowest price and the highest price. In our equations, we use the earliest departure price since this seems to be the most uniform, while the cheapest and most expensive fares tend to vary greatly depending on the time of departure. However, we also present the results when using the lowest and highest prices as the dependent variable, in the Appendix, but these results do not differ from our preferred regressions. Whenever two or more companies cover a route we compute their respective shares in terms of total frequencies and use this to calculate the weighted mean price for the route. We follow the same procedure for the average speed variable.

We include as an explanatory variable the Herfindahl-Hirschman Index (HHI), which measures the level of concentration on any given route. The HHI is calculated as the sum of the shares of bus companies operating on the route in terms of frequencies, thus capturing the intensity of intramodal competition.

Additionally, we include two dummy variables that capture the potential intermodal competition on a route. The first dummy is the variable train, which takes a value of one if a direct train service is operated on the route, and 0 otherwise. The second dummy is the variable plane, which takes a value of one if a direct flight connection exists on a given route, and 0 otherwise.

\footnotetext{
${ }^{10}$ To convert UK pounds and Swedish krona to euros, we used the official exchange rate provided by the ECB on the day of research.

${ }^{11}$ It was an ordinary working day, the second Tuesday in the month.
} 
We also include a set of control variables that are drawn from the Eurostat database, in an attempt to capture the demand for bus services. To maximize accuracy, we use the lowest level of Nomenclature of Units for Territorial Statistics (NUTS) available, that is the NUTS 3. As in all gravity models, we use the weighted mean values of the population at the origin and destination for the control variables. Typically, gravity models are used to estimate demand on interurban transport routes. In models of this kind, demand between two points depends positively on the economic and demographic size of the origin and destination, and negatively on their distance apart. Furthermore, we also include a variable that represents the length and speed of the services, to account for the quality and costs of the IBS.

Finally, we include a list of dummy variables, corresponding to each specific country (Spain, the United Kingdom, Germany, France, Italy and Sweden), which take a value of 1 whenever a route is completed in the corresponding country and 0 otherwise. With the inclusion of these variables we can compare the IBS between these countries. A possible explanation for the differences in results may be found in the different regulatory system operating in each country: competition in the market prevails in Germany, Italy, Sweden and the United Kingdom, while competition for the market prevails in Spain.

We estimate additional models, including as explanatory variables the interaction between the dummy of each country and the two most relevant continuous variables of our analysis; the GDP per capita and the Herfindahl-Hirschman Index. Note that in these additional regressions we cannot include the dummy variables for each country and the interactions must be added separately for GDP per capita and the HHI. The reason is that the variation inflation factor that measures the multicollinearity increases to more than 10,000 for the country dummies and the interaction variables when they are jointly considered, so the individual identification of variables may get distorted. This 
may be explained by the low number of observations in our sample. This is a limitation of our data that must be taken into account in the interpretation of results.

All the variables, except for the dummies, are in logs. Table 2 shows the descriptive statistics of the variables used in the empirical analysis.

\section{Insert table 2 about here}

\subsection{Empirical strategy}

The baseline equation that we estimate for the route $k$ is as follows:

$$
\begin{aligned}
Y_{k}= & \alpha_{0}+\alpha_{1} \log \left(\text { HHI }_{k}\right)+\alpha_{2} \log \left(\text { length }_{k}\right)+\alpha_{3} \log \left(\text { speed }_{k}\right)+\alpha_{4} \text { train }_{k}+\alpha_{5} \text { plane }_{k}+\alpha_{6} \log \left(\text { wgdp }_{k}\right)+ \\
& \alpha_{7} \log \left(\text { wpop }_{k}\right)+\varepsilon_{\mathrm{k}}
\end{aligned}
$$

where $Y_{k}$ is, respectively, $\log \left(\right.$ price $\left./ \mathrm{km}_{k}\right)$ and $\log \left(\right.$ frequency $\mathrm{y}_{k}$ ). We use the set of independent variables to control for demand (GDP per capita $=w g d p$, Population $=w p o p)$, costs $($ length, average speed) and competition from alternative modes (train and plane). We also control for market concentration on a route $(H H I)$.

We also estimate additional equations to identify possible differences between IBS regulation systems. In a second equation, besides the above explanatory variables, we include a set of dummy variables corresponding to the countries analyzed. In all cases, our reference country is Spain. In the third and fourth equations, we include the interaction between the country dummy variables and the HHI and GDP per capita variables, respectively.

We estimate the equations using the same explanatory variables through a seemingly unrelated regression (SUREG) technique that accounts for a correlation between the error terms of the two equations. Standard errors are robust to heteroscedasticity. 


\section{Expected results of explanatory variables}

\subsection{Price per kilometer}

In the price per kilometer regression we expect a positive sign for the coefficient of the HHI variable. More (less) concentrated routes should charge higher (lower) prices, as companies use their market power to increase prices. In the case of IBS in Ireland, Ahern and Tapley (2008) show that on routes where there is less competition between bus services, the prices are higher. Likewise, we expect population to have a positive effect on the final price per kilometer, as routes that link more populated cities should have more demand.

The significance of the GDP per capita variable in the price equation is unclear. On the one hand, the demand for bus services may be higher in richer cities as users have more financial resources. On the other hand, the characteristics of bus transport, tending to be cheaper but also slower than other modes, could mean that the more affluent passengers prefer to use faster and more expensive transport alternatives, such as trains or planes. Furthermore, the price-elasticity of demand may be conditioned by the economic status of users. Thus, the expected effect of GDP per capita is unclear.

As Friebel and Niffka (2009) point out, the presence of intermodal competition between railroad and planes has an effect on prices. We believe that intermodal competition in IBS routes can also lower prices. Thus, we expect the coefficient associated with the train and plane variables to be negative. This negative effect is expected to be especially marked in the case of rail, given that for its specific users this mode probably represents a better substitute for IBS than traveling by air. Indeed, flying, as well as being faster, is much more expensive than traveling by bus, which means these two transportation modes may not be direct competitors. Thus, it would not be surprising if the availability of a flight covering a given route has no impact on bus prices and frequencies.

The variable length measures the distance between city pairs. The possible presence of distance economies would mean that this variable could have a negative impact on the price per kilometer. In 
this regard, the same fixed costs can apply to a service with a higher output (in this case a greater number of kilometers). Alternatively, it might be the case that total costs increase at a rate that is less than proportional to distance. Note that, as buses are generally slower than other modes of transportation (certainly planes and usually trains), the relative competitiveness - and therefore the prices - of buses vis-à-vis other transportation modes may decrease with distance.

Finally, for the average speed variable, two possible effects may emerge. A greater average speed leads to higher fuel consumption. In such cases, it is usual that firms transfer this cost directly to the users by increasing fares. Faster journeys may also be considered as "superior" services since they require less time, and this should also have a positive repercussion on prices.

However, a greater average speed may also result in cost reductions. If this is the case, we would expect a negative relationship between these two variables. In the case of the train for instance, an increase in the operative speed increases both the capacity of the system and the capacity to attract more passengers (Freyss et al., 2013). The same could apply to the interurban bus market. Higher average speeds allow buses to make more journeys per day. When this is true, firms face a crucial cost reduction: a smaller bus fleet and fewer personnel are required to cover a route. Likewise, higher average speeds are likely to be related to fewer bus stops and a better infrastructure, which would also help reduce costs ${ }^{12}$. If higher average speeds are related to better infrastructure and roads, then cars represent a serious threat to the bus since they can cover the same distance in considerably less time. Hence, the relative competitiveness of buses decreases with faster and better routes. Thus, one of the most effective ways by which the bus can compete with alternative modes is via prices. The average IBS speed in our sample ranges from 35 to $89 \mathrm{~km} / \mathrm{h}$ with a mean of $67 \mathrm{~km} / \mathrm{h}$. These values would strengthen the idea of a negative relationship between the two variables.

\footnotetext{
${ }^{12}$ Fuel consumption is higher when the vehicle has to accelerate. Constant average speeds and a minimum number of stops ensure a smooth and more efficient use of fuel.
} 
In those countries operating a more market-oriented regulatory framework, including the UK, Germany and Sweden, we expect prices to be lower than in those countries in which the market is more closely regulated. Preston (2001), in a study of the deregulated British system, reports that the price per kilometer for the urban bus is $23 \%$ lower than that in limited competition systems and $51 \%$ lower than in regulated systems. In our sample, only Spain has a regulatory system in which firms compete for the market through competitive tendering, while in the other five countries the firms compete directly in the market. Consequently, we expect the prices in Spain to be higher than in the rest of the countries.

\subsection{Frequency}

In the transportation sector, daily frequency is one of the key variables affecting quality. With higher levels of frequency, customers have more options for adapting the journey to their needs, while the waiting time for the next bus service is reduced.

The variable capturing the level of market concentration (HHI) is expected to have a negative impact on frequency. Ellis and Silva (1998), Oldale (1998) and Gomez-Lobo (2007) all show that, in the bus sector, firms compete in terms of service frequencies rather than in terms of price. If this is the case, then we would expect daily frequency to increase with competition.

The distance variable is also expected to have a negative effect. Demand on a route between two cities, according to gravity models, depends negatively on the distance between them (Anas, 1983; Kingsley and Fotheringham, 1984). Moreover, longer distances tend to make the bus less attractive in relation to other modes of transport. Finally, shorter distances allow firms to offer more journeys without having to increase the size of their fleet.

The sign of the coefficient of the speed variable is expected to be positive. As discussed, higher average speeds allow firms to undertake more journeys per day without incurring higher costs. 
In the case of alternative modes of transportation, two opposite effects may impact daily frequencies. On the one hand, the presence of alternative modes on a route means demand is split between different suppliers. If this is the case, the expected sign for the train and plane variables in the daily frequency equation should be negative. On the other hand, the presence of alternative modes points to a high level of demand on a route. In addition, bus firms may be required to provide more frequent services to compete with other modes of transport. Hence, the expected effect of alternative modes on daily frequency is unclear.

Population is a good proxy for demand. Thus, we expect that higher levels of population will increase daily frequency of services. In contrast, the expected sign of the GDP per capita variable is, a priori, less clear. A positive relationship between this variable and daily frequency should be recorded if demand is higher on routes with richer endpoints. Yet, it might also be the case that higher levels of income are related to lower frequency levels. As we mention above, richer people can afford more expensive transportation alternatives, which means demand for IBS could be lower and hence frequency levels will also be lower.

Finally, Table 1 should help us predict frequencies in the different countries analyzed. One of the variables included in the table is the total number of daily services offered in each country. It is readily apparent that two countries, France and Italy, supply a considerably lower rate of daily frequencies. Therefore, it is reasonable to expect that the two dummy variables identifying these two countries will present a negative sign. As for the rest of the countries, although there are differences in the daily frequency rates, we cannot tell, a priori, whether these differences are statistically significant.

\section{Results}

Table 3 shows the results of the price equation. The coefficient associated with distance is negative and highly significant, indicating that the longer the journey, the lower the price per kilometer. In the case of average speed, the results also show a negative and significant effect on prices, pointing to 
the presence of cost reductions associated with higher average speeds. A $20 \%$ increase in the average speed, for example, rising from an average of $65 \mathrm{~km} / \mathrm{h}$ to an average of $78 \mathrm{~km} / \mathrm{h}$, is related to a decrease of about $14 \%$ in the price per kilometer. Alternatively, the strategy that firms seem to adopt when using better, faster routes is to cut their prices so as to be able to compete with faster modes of transport.

\section{Insert table 3 about here}

The presence of train services on a route leads to lower prices per kilometer. Indeed, our results show that whenever a route is also covered by a rail link, prices are, on average, about 14-17\% lower. However, this is not the case for the plane, the effect of which on bus prices is not statistically different from zero. This result seems to confirm that this mode of transport is not perceived by passengers and firms as a substitute.

As expected, the variable HHI positively affects prices although it is not statistically significant. Thus, such results suggest that price competition between IBS operators is weak. Furthermore, weighted population behaves according to our expectations but it is only statistically significant at the $10 \%$ level in the equation that do not consider country dummies.

Interestingly, the coefficient of the GDP per capita variable presents a negative sign. This indicates a strong, negative relationship between GDP per capita and prices. A $10 \%$ increase in the GDP per capita of the route's endpoint leads to a 3-4\% decrease in the price per kilometer. This result shows that the price setting practices of bus firms follow a regressive scheme for a service used primarily by low-income groups. Regarding this point, note that the estimation in the appendix confirms the negative relationship between prices and GDP per capita when we consider as a dependent variable the lowest price.

It should be stressed that, with the inclusion of the country dummy variables, the goodness of fit of the regression increases significantly. The $\mathrm{R}^{2}$ value rises from 0.43 in the first equation to 0.61 
when we include the country variables. This indicates that differences across the countries in our sample account for an important part of the pricing policies followed by bus firms.

When we examine the price per kilometer in our reference country, Spain, the differences with the five other countries are significant. With all other variables held constant, the results show that the price per kilometer in Spain is between 12\% and 36\% higher than in the other five countries. This result could be a direct consequence of the regulatory system operating in Spain, where firms compete for the market rather than in it. On the other hand, the magnitude of the differences could mean that the result is capturing other unobserved country characteristics, such as different fuel prices, tax systems or other elements. Note here that the estimation reported in the appendix shows that differences between countries are less clear when we consider the lowest price.

When we consider the interaction between HHI and the country dummy variables, we find that the relationship between prices and $\mathrm{HHI}$ is stronger for Spain than for the rest of the countries. A potential explanation for this result is that in those countries with competition in the market the potential threat of the entry of other firms may restrict the price setting behavior of incumbents, even if the $\mathrm{HHI}$ is high. In this regard, note that barriers to entry are small in economic terms in the IBS market, but in Spain the presence of administrative barriers neutralizes any threat of entry from potential competitors. Otherwise, the Spanish scheme seems to perform better in terms of regressiveness, as the negative relationship between prices and GDP per capita is stronger for the rest of countries.

Table 4 shows the results of the frequency equation. The signs of the coefficients associated with HHI, speed, length, GDP per capita and population variables are as expected. In this regard, we find a strong negative relationship between the level of concentration on a route (HHI) and the level of frequency. In line with the previous literature, this would indicate that firms compete in terms of frequencies. In contrast, in the case of intermodal competition, none of the coefficients associated with these variables is statistically different from zero. 
Thus, we find evidence that intermodal competition in the interurban bus market is based on prices while intramodal competition is based on frequencies. Indeed, the variable that measures the intensity of intramodal competition (the Herfindahl-Hirschman Index) is not statistically significant in the pricing equation while it is negative and statistically significant in the frequency equation. This means that a decrease in intramodal competition (measured by the increase in the Herfindahl-Hirschman Index) leads to less frequency but not to higher prices. In contrast, the presence of train services on the route leads to lower prices but does not have a relevant effect on frequency.

Likewise, we find that higher average speeds have a positive effect on daily frequencies, the associated coefficient being positive and highly significant. As discussed above, higher average speeds allow firms to increase frequencies without having to increase costs. If we use the previous example, a $20 \%$ increase in average speed leads to a $22-26 \%$ increase in daily frequency.

As expected, the coefficient associated with the distance variable between route endpoints is also negative. The demand for bus services decreases with the length of the route, and so companies tend to offer fewer services. GDP per capita and population have a clear effect on the number of daily services, being indicative of the impact on demand that these two variables are likely to have. Ten percent increases in GDP per capita and population, at the endpoints of the route, are related to increases of 4 and $3 \%$ in frequencies, respectively.

\section{Insert table 4 about here}

Finally, when we add the country dummy variables to the equation, the signs for all the previously considered explanatory variables do not change. As in the price specification, the goodness of fit also increases considerably with the inclusion of the country dummy variables. Now the $\mathrm{R}^{2}$ value rises from 0.55 to 0.68 .

When comparing the daily frequency of services in Spain with that in the other five countries, the results show that, all other variables being held constant, Spain's daily frequency is on average $44 \%$, 
$41 \%$ and $23 \% \%$ higher than that of France, Italy and Sweden, respectively. With respect to the UK and Germany, the differences are not statistically different from zero. Differences between countries are less marked when we consider the interaction variables. In comparison to Spain, it seems that the relationship between frequencies and HHI is stronger for France, Italy and, to a lower extent, Sweden. Thus, the intensity of intramodal competition may be higher in the latter countries. Otherwise, the relationship between frequencies and GDP per capita is stronger for Spain than for the aforementioned countries.

\section{Conclusions}

In this paper, we have presented two equations which, in combination with a dataset for several countries, has enabled us to identify the determinants of prices and daily frequencies in the interurban bus sector.

Controlling for several explanatory factors, we find that bus fares are lower on routes with richer endpoints. Hence, we provide some evidence of regressive fare-setting schemes in the IBS of the European countries included in our analysis. In contrast, daily frequencies are higher on routes with richer endpoints. This suggests that lower income cities not only suffer from lower quality levels, measured in terms of daily frequencies, but also have to face higher prices. Consequently, the fare systems employed by the IBS in Europe seem to be detrimental to low-income users. The higher prices in poorer cities may be a consequence of lower price elasticities. Low-income groups have usually fewer travel options; they are less likely to own a car and air fares may not be affordable for them. Thus, they are more likely to be captive users and less able to react to price increases by switching mode. 
To this point, note that fares are set by operators and not by the authorities. This is even the case for Spain where operators must adapt to a price-cap regulation. The regressive nature of the systems points to the need for authorities to consider to require (and even finance) certain social rebates.

Additionally, we find that in the interurban bus market intramodal competition is based essentially on frequencies, while intermodal competition is based on prices. Indeed, the variable HHI that measures the degree of competition between bus firms is only significant in the frequency equation, while it does not present any effect on prices. In line with the previous literature, this suggests that bus firms compete in frequencies. In contrast, the presence of train services on a given route has a marked effect on bus prices but not on frequencies.

We also find significant differences across the countries analyzed in terms of the setting of prices and frequencies. A possible explanation for these differences might lie in the differences in their respective regulatory systems. In the countries that have liberalized their markets, prices are lower to those in a country like Spain where competition is for the market.

However, the differences in prices may also be attributable to other unobserved country characteristics and so further research is needed to examine the impact of the different regulatory models on prices and frequencies in the interurban bus market. To this end, further research could compare our approach with a game theory approach that considers a discrete choice model for demand analysis.

\section{References}

Aarhaug, J. and Fearnley, N. (2016) Deregulation of the Norwegian Long Distance Express Coach Market. Transport Policy, 46, 1-6. 
Abuhamoud, M., Rahmat, R. and Ismail, A. (2011) Modeling of Transport Mode in Libya a Binary Logit Model for Government Transportation Encouragement. Australian Journal of Basic and Applied Sciences, 5, 1291-1296.

Ahern, A. and Tapley, N. (2008) The use of stated preference techniques to model modal choices on interurban trips in Ireland. Transportation Research Part A, 42, 15-27.

Albalate, D., Bel, G. and Calzada, J. (2012) Governance and regulation of urban bus transportation Using partial privatization to achieve the better of two worlds. Regulation and Governance, 6, 83100.

Alexandersson, A., Hultén, S., Fearnley, N., Longva, F. (2014) Impact of regulation on the performances of long-distance transport services: A comparison of the different approaches in Sweden and Norway. Research in Transportation Economics, 29, 212-218.

Anas, A. (1983) Discrete Choice Theory, Information Theory and the Multinomial Logit and Gravity Models. Transportation Research Part B, 17, 13-21.

Augustin, K., Gerike, R., Martinez Sanchez, M.J., Ayala, C. (2014) Analysis of intercity bus markets on long distances in an established and a young market: The example of the U.S. and Germany. Research in Transportation Economics, 48, 245-254.

Balcombe, R., Mackett, R., Paulley, N., Preston, J., Shires, J., Titheridge, H., Wardman, M. and White, P. (2004) The demand for public transport a practical guide, TRL Report 593.

Bataille, M. and Steinmetz, A. (2013) Intermodal competition on some routes in transportation networks: The case of inter urban buses and railways, DICE Discussion Paper No. 84-.

Barbadillo, R. Pertierra, J. Herce, J. Hernández, P. and Vizcaíno, D. (2014) El transporte en autocar, una solución sostenible para la movilidad de las personas, Ediciones Empresa Global, Madrid. 
Blayac, T. and Bougette, P. (2017) Should I go by bus? The liberalization of the long-distance bus industry in France. Transport Policy, 56, 50-62.

Borcherdinget, T. Pommerehne, W. and Schneider F. (1982) Comparing the efficiency of private and public production the evidence from five countries. Zeitschrift für Nationalökonomie 89, 12756.

Chapman, L. (2007) Transport and Climate Change Review. Journal of Transport Geography, 5, 354-367.

DfT (2004) The Future of Transport, a Network for 2030, UK Department for Transport, London.

Dobson, P. and Waterson, P. (1997) Countervailing power and consumer prices, The Economic Journal, 107, 418-430.

Dürr, N.S. and Hüschelrath, K. (2017). Patterns of entry and exit in the deregulated German interurban bus industry. Transport Policy, 59, 196-208.

Dürr, N.S., Heim, S. and Hüschelrath, K. (2016) Deregulation, competition, and consolidation the case of the German interurban bus industry. Journal of Transport Economics and Policy, 50, 164188.

Ellis, J. and Silva, E. (1998) British bus deregulation competition and demand coordination. Journal of Urban Economics, 43, 336-361.

European Commission (2009) Study of passenger transport by coach, European Commission, Brussels.

Fenebús (2014) Boletín informativo de la Federación Nacional Empresarial de Transporte en Autobús, Fenebús, Madrid.

Filippini, M., Koller, M. and Masiero, G. (2015) Competitive tendering versus performance-based negotiation in Swiss public transport. Transportation Research Part A, 82, 158-168. 
Freyss, M., Giesen, R. and Muñoz, J. (2013) Continuous approximation for skip-stop operation in the rail transit. Transportation Research Part C, 36, 419-433.

Friebel, G. and Niffka, M. (2009) The Functioning of inter-modal competition in the transportation market evidence from the entry of low-cost airlines in Germany. Review of Network Economics, 8, 189-211.

Gomez-Lobo, A. (2007) Why competition does not work in urban bus markets Some new wheels for some old ideas. Journal of Transport Economics and Policy, 41, 283-308.

Haynes, K. and Fotheringham, A. (1984) Gravity model overview, Gravity and Spatial Interaction Models, Sage, Newcastle upon Tyne.

Heil, M. and Pargal, S. (1991) Reducing Air Pollution from Urban Passenger Transport. A framework for Policy Analysis, The World Bank Development Research Group Infrastructure.

Ibarra-Rojas, O., Delgado, F., Giesen, R. and Muñoz, J. (2015) Planning, operation and control of bus transport systems. A literature review. Transportation Research Part B 77, 38-75.

Jansson, J.O. (1994) Accident externality charges. Journal of Transport Economics and Policy, 28, $31-43$.

Jørgensen, F., Pedersen, P.A. and Volden R. (1997) Estimating the inefficiency in the Norwegian bus industry from stochastic cost frontier models. Transportation, 24, 421-33.

Knorr, A. and Lueg-Arndt, A. (2016) Intercity bus deregulation in Germany - Intramodal and intermodal effects after two years. Research in Transportation Economics, 59, 323-329.

Mouwen, A. and van Ommeren, J. (2016) The effect of contract renewal and competitive tendering on public transport costs, subsidies and ridership. Transportation Research Part A, 87, 78-89.

Oldale, A. (1998) Local bus deregulation and timetable inability. Working Paper (London School of Economics). 
Preston, J. (2001) Regulation policy in land passenger transportation in Europe. Working Paper (University of Oxford).

Rizzi, L.I. and De La Maza, C. (2017) The external costs of private versus public road transport in the Metropolitan Area of Santiago, Chile. Transportation Research Part A, 98, 123-140.

Rojo, M., Gonzalo-Orden, H., dell'Olio, L. and Ibeas, A. (2012) Relationship between service quality and demand for inter-urban buses. Transportation Research Part A, 46, 1716-1729.

Scheffler, R., Hartwig, K. and Malina, R. (2013) The Effects of Ownership Structure, Competition, and Cross-Subsidisation on the Efficiency of Public Bus Transport. Journal of Transport Economics and Policy, 47, 371-386.

Sen, A.K., Tiwari, G. and Upadhyay, V. (2010) Estimating marginal external costs of transport in Delhi. Transport Policy, 17, 27-37.

Stanley, J. and Watkiss, P., (2003) Transport energy and emissions buses. In Hensher, D.A. and Button, K.J. (Eds.), Handbooks in Transport 4 Handbook of Transport and the Environment. Emerald Group Publishing, London, 227-246.

Taylor, Z. and Ciechanski, A. (2008) What Happened to the National Road Carrier in a PostCommunist Country? The Case of Poland's State Road Transport. Transport Reviews, 28, 619640.

Van de Velde, D. (2009) Long-Distance Bus Services in Europe Concessions or Free Market? Joint Transport Research Centre Discussion Paper, No. 21.

Van de Velde, D. (2014) Market initiative regimes in public transport in Europe: Recent developments, Research in Transport Economics, 48, 33-40.

Vining, A. R. and A. B. Boardman (1992) Ownership versus competition efficiency in public enterprise. Public Choice, 73, 205-39. 
Walter, M., Haunerland, F., Moll, R. (2011) Heavily regulated, but promising prospects: Entry in the German Express Coach Market. Transport Policy, 18, 373-381.

White, P. and Robbins, D. (2012) Long-term development of express coach services in Britain, Research in Transport Economics, 36, 30-38. 


\section{TABLES}

Table 1. Number of routes and daily frequencies in each country

\begin{tabular}{|c|c|c|c|c|c|c|c|}
\hline Country & Firm & Num. routes & $\%$ & Daily freq. & $\%$ & Relative freq. & $\%$ \\
\hline \multirow[t]{7}{*}{ Spain } & Alsa & 28 & 73.7 & 187 & 81.7 & & \\
\hline & Socibus & 3 & 7.9 & 16 & 7.0 & & \\
\hline & $\begin{array}{l}\text { Grupo aut. } \\
\text { Jimenez }\end{array}$ & 3 & 7.9 & 7 & 3.1 & & \\
\hline & Bilmanbus & 2 & 5.3 & 3 & 1.3 & & \\
\hline & Avanza bus & 1 & 2.6 & 10 & 4.4 & & \\
\hline & Daibus & 1 & 2.6 & 6 & 2.6 & & \\
\hline & Total & 38 & & 229 & & & \\
\hline \multirow[t]{5}{*}{ UK } & National Express & 19 & 51.4 & 69 & 13.3 & & \\
\hline & $\underline{2 \text { firms }}$ & 18 & 48.6 & 449 & 86.7 & & \\
\hline & $\mathrm{NE}$ & & & & & 258 & 57.5 \\
\hline & Megabus & & & & & 191 & 42.5 \\
\hline & Total & 37 & & 518 & & & \\
\hline \multirow[t]{5}{*}{ Sweden } & Swebus & 7 & 28.0 & 18 & 10.78 & & \\
\hline & 2 firms & 18 & 72.0 & 149 & 89.22 & & \\
\hline & Swebus & & & & & 93 & 62.4 \\
\hline & Nettbus & & & & & 58 & 38.9 \\
\hline & Total & 25 & & 167 & & & \\
\hline \multirow[t]{7}{*}{ Italy } & Baltour & 18 & 72.0 & 25 & 55.56 & & \\
\hline & Soc. Marino Srl. & 4 & 16.0 & 11 & 24.44 & & \\
\hline & Sais autolinee & 1 & 4.0 & 2 & 4.44 & & \\
\hline & 2 firms & 2 & 8.0 & 7 & 15.56 & & \\
\hline & Baltour & & & & & 5 & 71.4 \\
\hline & Consr. Autolinee & & & & & 2 & 28.6 \\
\hline & Total & 25 & & 45 & & & \\
\hline \multirow[t]{7}{*}{ France } & Eurolines & 8 & 61.5 & 13 & 37.14 & & \\
\hline & Megabus & 1 & 7.7 & 2 & 5.71 & & \\
\hline & Starshipper & 1 & 7.7 & 1 & 2.86 & & \\
\hline & $\underline{2 \text { firms }}$ & 3 & 23.1 & 19 & 54.29 & & \\
\hline & Idbus & & & & & 12 & 63.2 \\
\hline & Eurolines & & & & & 7 & 36.8 \\
\hline & Total & 13 & & 35 & & & \\
\hline \multirow[t]{12}{*}{ Germany } & Flixbus & 8 & 19.51 & 51 & 13.86 & & \\
\hline & Eurolines & 1 & 2.44 & 1 & 0.27 & & \\
\hline & Postbus & 1 & 2.44 & 1 & 0.27 & & \\
\hline & $\underline{2 \text { firms }}$ & 22 & 53.66 & 163 & 44.29 & & \\
\hline & Flixbus & & & & & 131 & 80.4 \\
\hline & Postbus & & & & & 32 & 19.6 \\
\hline & $\underline{3 \text { firms }}$ & 3 & 7.32 & 53 & 14.40 & & \\
\hline & Flixbus & & & & & 33 & 62.3 \\
\hline & Postbus & & & & & 10 & 18.9 \\
\hline & Berlinlinenbus & & & & & 10 & 18.9 \\
\hline & 3 firms & 6 & 14.63 & 99 & 26.90 & & \\
\hline & $\overline{\text { Flixbus }}$ & & & & & 70 & 70.7 \\
\hline
\end{tabular}




\begin{tabular}{|c|c|c|c|c|c|c|c|}
\hline & Postbus & & & & 22 & 22.2 \\
\hline & Eurolines & & & & & 7 & 7.1 \\
\hline & Total & $\mathbf{4 1}$ & & $\mathbf{3 6 8}$ & & & \\
\hline
\end{tabular}

Note: '2 (3) firms' indicates that there are 2 (or 3) firms providing the service. The names of the firms are shown below it.

Table 2: Explanatory variables and descriptive statistics

\begin{tabular}{|c|c|c|c|c|c|c|}
\hline Variable & Description & Obs. & Mean & Standard Dev. & Min. & Max \\
\hline Service & $\begin{array}{c}\text { Binary variable: 1 if a service exists } \\
\text { on a route, 0 otherwise }\end{array}$ & 270 & 0.6556 & 0.4761 & 0 & 1 \\
\hline Price/km & $\begin{array}{c}\text { Price per kilometer PPP of the } \\
\text { earliest route }\end{array}$ & 177 & 0.0688 & 0.0396 & 0.01037 & 0.20 \\
\hline Frequency & Daily frequency on a route & 177 & 7.6949 & 9.7955 & 1 & 90 \\
\hline HHI & Herfindahl-Hirschman Index & 177 & 8416.8 & 2062.8 & 3979 & 10000 \\
\hline Length & $\begin{array}{c}\text { Distance between the two paired } \\
\text { links (km) }\end{array}$ & 270 & 455.6 & 277.2 & 33 & 1466 \\
\hline Speed & Average speed of the route (km/h) & 177 & 66.82 & 10.69 & 35.42 & 88.68 \\
\hline Train & $\begin{array}{c}\text { Binary variable: 1 if a train covers } \\
\text { the route, 0 otherwise. }\end{array}$ & 270 & 0.7074 & 0.4558 & 0 & 1 \\
\hline Plane & $\begin{array}{c}\text { Binary variable: 1 if a plane covers } \\
\text { the route, 0 otherwise. }\end{array}$ & 270 & 0.5778 & 0.4948 & 0 & 1 \\
\hline Wgdp & $\begin{array}{c}\text { Weighted GDP per capita PPP, } \\
\text { NUTS 3 level }\end{array}$ & 270 & 33975 & 17674 & 16400 & 117094 \\
\hline Wpop & Weighted population, NUTS 3 level & 270 & 1624952 & 1247366 & 158427 & 5962 \\
\hline
\end{tabular}


Table 3. Dependent variable: Price per kilometer. Seemingly unrelated regression

\begin{tabular}{|c|c|c|c|c|}
\hline & Baseline & $\begin{array}{l}\text { With country } \\
\text { dummies }\end{array}$ & $\begin{array}{c}\text { With interactions (country } \\
\text { dummies X HHI) }\end{array}$ & $\begin{array}{c}\text { With interactions (country } \\
\text { dummies X Wgdp) }\end{array}$ \\
\hline Cons & $1.66(0.86)^{*}$ & $1.93(0.79)^{* *}$ & $1.73(0.77)^{* *}$ & $1.81(0.78)^{* * *}$ \\
\hline HHI & $0.22(0.14)$ & $0.14(0.13)$ & $0.19(0.13)$ & $0.13(0.13)$ \\
\hline Length & $-0.33(0.07) * * *$ & $-0.29(0.06)^{* * *}$ & $-0.29(0.06)^{* * *}$ & $-0.29(0.06)^{* * *}$ \\
\hline Speed & $-0.67(0.22)^{* * *}$ & $-0.72(0.19)^{* * *}$ & $-0.71(0.19)^{* * *}$ & $-0.74(0.19)^{* * *}$ \\
\hline Train & $-0.17(0.04)^{* * *}$ & $-0.14(0.04)^{* * *}$ & $-0.14(0.03)^{* * *}$ & $-0.14(0.03)^{* * *}$ \\
\hline Plane & $-0.01(0.03)$ & $0.02(0.03)$ & $0.02(0.03)$ & $0.02(0.03)$ \\
\hline Wgdp & $-0.42(0.09) * * *$ & $-0.33(0.08)^{* * *}$ & $-0.33(0.08)^{* * *}$ & $-0.29(0.09)^{* * *}$ \\
\hline Wpop & $0.10(0.05)^{*}$ & $0.04(0.05)$ & $0.04(0.05)$ & $0.03(0.05)$ \\
\hline UK & - & $-0.12(0.05)^{* *}$ & - & - \\
\hline Germany & - & $-0.23(0.05) * * *$ & - & - \\
\hline France & - & $-0.23(0.06)^{* * *}$ & - & - \\
\hline Italy & - & $-0.36(0.04) * * *$ & - & - \\
\hline Sweden & - & $-0.17(0.05)^{* * *}$ & - & - \\
\hline UK X HHI & - & - & $-0.03(0.01)^{* *}$ & - \\
\hline Germany X HHI & - & - & $-0.06(0.01)^{* * *}$ & - \\
\hline France X HHI & - & - & $-0.06(0.01)^{* * *}$ & - \\
\hline Italy X HHI & - & - & $-0.09(0.01) * * *$ & - \\
\hline Sweden X HHI & - & - & $-0.04(0.01)^{* * *}$ & - \\
\hline UK X Wgdp & - & - & - & $-0.03(0.01)^{* *}$ \\
\hline Germany X Wgdp & - & - & - & $-0.05(0.01)^{* * *}$ \\
\hline France X Wgdp & - & - & - & $-0.05(0.01)^{* * *}$ \\
\hline Italy X Wgdp & - & - & - & $-0.08(0.009)^{* * *}$ \\
\hline Sweden X Wgdp & - & - & - & $-0.04(0.01) * * *$ \\
\hline $\mathbf{N}$ & 177 & 177 & 177 & 177 \\
\hline $\mathbf{R}^{2}$ & 0.43 & 0.61 & 0.61 & 0.61 \\
\hline
\end{tabular}

Note: Standard errors in parentheses. Statistical significance at 1\% (***), 5\% (**), $10 \%(*)$. 
Table 4 Dependent variable: Daily frequency. Seemingly unrelated regression

\begin{tabular}{|c|c|c|c|c|}
\hline 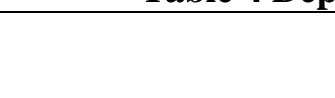 & Baseline & $\begin{array}{l}\text { With country } \\
\text { dummies }\end{array}$ & $\begin{array}{c}\text { With interactions (country } \\
\text { dummies X HHI) }\end{array}$ & $\begin{array}{c}\text { With interactions (country } \\
\text { dummies X Wgdp) }\end{array}$ \\
\hline Cons & $3.16(1.39)^{* *}$ & $2.83(1.29)^{* *}$ & $2.73(1.27)^{* *}$ & $2.69(1.27)^{* *}$ \\
\hline HHI & $-1.46(0.23)^{* * *}$ & $-1.39(0.22)^{* * *}$ & $-1.36(0.21)^{* * *}$ & $-1.38(0.22)^{* * *}$ \\
\hline Length & $-0.73(0.11) * * *$ & $-0.72(0.10)^{* * *}$ & $-0.72(0.10) * * *$ & $-0.72(0.10)^{* * *}$ \\
\hline Speed & $1.15(0.36)^{* * *}$ & $1.30(0.32)^{* * *}$ & $1.30(0.32)^{* * *}$ & $1.29(0.03)^{* * *}$ \\
\hline Train & $0.05(0.06)$ & $0.04(0.06)$ & $0.04(0.06)$ & $0.03(0.06)$ \\
\hline Plane & $0.03(0.06)$ & $0.06(0.05)$ & $0.06(0.05)$ & $0.05(0.05)$ \\
\hline Wgdp & $0.44(0.14)^{* * *}$ & $0.40(0.13)^{* * *}$ & $0.40(0.13)^{* * *}$ & $0.42(0.14)^{* * *}$ \\
\hline Wpop & $0.28(0.09)^{* * *}$ & $0.30(0.09)^{* * *}$ & $0.30(0.09)^{* * *}$ & $0.31(0.09)^{* * *}$ \\
\hline UK & - & $0.003(0.09)$ & - & - \\
\hline Germany & - & $-0.04(0.09)$ & - & - \\
\hline France & - & $-0.41(0.10)^{* * *}$ & - & - \\
\hline Italy & - & $-0.44(0.07)^{* * *}$ & - & - \\
\hline Sweden & - & $-0.23(0.09)^{* *}$ & - & - \\
\hline UK X HHI & - & - & $0.0001(0.02)$ & - \\
\hline Germany X HHI & - & - & $-0.01(0.02)$ & - \\
\hline France X HHI & - & - & $-0.10(0.02)^{* * *}$ & - \\
\hline Italy X HHI & - & - & $-0.11(0.01)^{* * *}$ & - \\
\hline Sweden X HHI & - & - & $-0.06(0.02)^{* *}$ & - \\
\hline UK X Wgdp & - & - & - & $0.001(0.02)$ \\
\hline Germany X Wgdp & - & - & - & $-0.01(0.02)$ \\
\hline France X Wgdp & - & - & - & $-0.09(0.02)^{* * *}$ \\
\hline Italy X Wgdp & - & - & - & $-0.10(0.01) * * *$ \\
\hline Sweden X Wgdp & - & - & - & $-0.05(0.02)^{* *}$ \\
\hline $\mathbf{N}$ & 177 & 177 & 177 & 177 \\
\hline $\mathbf{R}^{2}$ & 0.55 & 0.68 & 0.68 & 0.68 \\
\hline
\end{tabular}

Note: Standard errors in parentheses. Statistical significance at $1 \%(* * *), 5 \%(* *), 10 \%(*)$. 


\section{APPENDIX}

Table A1. Dependent variable: price per $\mathrm{km} .1$ month in advance

\begin{tabular}{|c|c|c|c|}
\hline & Earliest & Lowest & Highest \\
\hline Cons & $1.93(0.79)^{* *}$ & $1.34(0.86)$ & $1.45(0.81)^{*}$ \\
\hline HHI & $0.14(0.13)$ & $0.23(0.14)$ & $-0.06(0.13)$ \\
\hline Length & $-0.29(0.06)^{* * *}$ & $-0.23(0.07)^{* * *}$ & $-0.29(0.06)^{* * *}$ \\
\hline Speed & $-0.72(0.19)^{* * *}$ & $-0.66(0.21)^{* * *}$ & $-0.34(0.20)^{*}$ \\
\hline Train & $-0.14(0.04)^{* * *}$ & $-0.11(0.04)^{* * *}$ & $-0.15(0.03)^{* * *}$ \\
\hline Plane & $0.02(0.03)$ & $0.02(0.03)$ & $-0.01(0.003)$ \\
\hline Wgdp & $-0.33(0.08)^{* * *}$ & $-0.32(0.09)^{* * *}$ & $-0.20(0.08)^{* *}$ \\
\hline Wpop & $0.04(0.05)$ & $-0.06(0.06)$ & $0.05(0.06)$ \\
\hline UK & $-0.12(0.05)^{* *}$ & $0.002(0.09)$ & $-0.03(0.05)$ \\
\hline Germany & $-0.23(0.05)^{* * *}$ & $-0.06(0.06)$ & $-0.25(0.05)^{* * *}$ \\
\hline France & $-0.23(0.06)^{* * *}$ & $-0.10(0.07)$ & $-0.26(0.06)^{* * *}$ \\
\hline Italy & $-0.36(0.04)^{* * *}$ & $-0.17(0.04)^{* * *}$ & $-0.37(0.04)^{* * *}$ \\
\hline Sweden & $-0.17(0.05)^{* * *}$ & $0.01(0.06)$ & $-0.20(0.06)^{* * *}$ \\
\hline $\mathbf{N}$ & 177 & 177 & 177 \\
\hline $\mathbf{R}^{\mathbf{2}}$ & 0.61 & 0.46 & 0.59 \\
\hline
\end{tabular}

Note: Standard errors in parentheses. Statistical significance at 1\% (***), 5\% (**), $10 \%(*)$. 